\title{
BMJ Acute electrocardiographic changes Open during smoking: an observational study
}

\author{
Sivasubramanian Ramakrishnan, Kinjal Bhatt, Akhilesh K Dubey, Ambuj Roy, \\ Sandeep Singh, Nitish Naik, Sandeep Seth, Balram Bhargava
}

To cite: Ramakrishnan S, Bhatt K, Dubey AK, et al. Acute electrocardiographic changes during smoking: an observational study. BMJ Open 2013;3:e002486. doi:10.1136/bmjopen-2012002486

- Prepublication history and additional material for this paper are available online. To view these files please visit the journal online (http://dx.doi.org/10.1136/ bmjopen-2012-002486).

Received 12 December 2012 Revised 5 February 2013 Accepted 7 March 2013

This final article is available for use under the terms of the Creative Commons Attribution Non-Commercial 2.0 Licence; see http://bmjopen.bmj.com

Department of Cardiology, All India Institute of Medical Sciences, New Delhi, India

\section{Correspondence to} Dr Balram Bhargava; balrambhargava@yahoo.com
ABSTRACT

Objective: To study the temporal relationship of smoking with electrophysiological changes.

Design: Prospective observational study.

Setting: Tertiary cardiac center.

Participants: Male smokers with atypical chest pain were screened with a treadmill exercise test (TMT). A total of 31 such patients aged $49.8 \pm 10.5$ years, in whom TMT was either negative or mildly positive were included. Heart rate variability (HRV) parameters of smokers were compared to those of 15 healthy nonsmoking participants.

Interventions: All patients underwent a $24 \mathrm{~h}$ Holter monitoring to assess ECG changes during smoking periods.

Results: Heart rate increased acutely during smoking. Mean heart rate increased from $83.8 \pm 13.7 \mathrm{bpm} 10 \mathrm{~min}$ before smoking, to $90.5 \pm 16.4 \mathrm{bpm}$ during smoking, $(p<0.0001)$ and returned to baseline after $30 \mathrm{~min}$. Smoking was also associated with increased ectopic beats (mean of $5.3 / \mathrm{h}$ prior to smoking to $9.8 / \mathrm{h}$ during smoking to $11.3 / \mathrm{h}$ during the hour after smoking; $p<0.001)$. Three patients $(9.7 \%)$ had significant ST-T changes after smoking. HRV index significantly decreased in smokers $(15.2 \pm 5.3)$ as compared to nonsmoking controls participants $(19.4 \pm 3.6 ; p=0.02)$, but the other spectral HRV parameters were comparable.

Conclusions: Heart rate and ectopic beats increase acutely following smoking. Ischaemic ST-T changes were also detected during smoking. Spectral parameters of HRV analysis of smokers remained in normal limits, but more importantly geometrical parameter-HRV index-showed significant abnormality.

\section{INTRODUCTION}

Cigarette smoking is strongly associated with an increase in coronary artery disease. Cigarette smoking increases the relative risk of coronary artery disease by 2.8-fold and 3.1-fold in young (35-64 years) men and women, respectively. ${ }^{1}$ Smoking has acute deleterious effects on the blood pressure and sympathetic tone, and it reduces the myocardial oxygen supply. Compared to nonsmokers, smokers have increased incidence

\section{ARTICLE SUMMARY}

Article focus

- The temporal relationship of smoking with ECG changes is not documented.

- This study describes the immediate effects of smoking on heart rate, ST-segment deviation, arrhythmias and cardiac autonomic function as measured by heart rate variability (HRV) using Holter monitoring.

Key messages

- Heart rate and ectopic beats increase acutely following smoking.

- Ischaemic ST-T changes were also noted during smoking.

- HRV index showed significant impairment among smokers.

Strengths and limitations of this study

- First study to look at the temporal relationship of ECG changes during smoking.

- Limitation-small sample size.

of coronary spasm and a reduced threshold for ventricular arrhythmias. ${ }^{2-4}$ Smoking is associated with increased ventricular premature beats, and it is a strong risk factor for sudden cardiac death. ${ }^{5}$ However, no study has evaluated the temporal relationship of these electrocardiographic changes with smoking.

There has been a growing recognition of the importance of the autonomic nervous system in cardiovascular disease. ${ }^{6}$ Various measures of heart rate variability (HRV) evaluate changes in beat-to-beat interval durations using ambulatory ECG. ${ }^{7}$ Various measures of HRV provide quantitative indicators of cardiac autonomic function. ${ }^{8}$ Studies have documented the increase in HRV shortly after smoking cessation. Changes in heart rate and HRV are also described in association with acute passive smoking or exposure to respirable suspended particles (RSP). To the best of our knowledge, this is the first report of HRV during acute exposure to cigarette smoking. The objective of 
this study was to evaluate the immediate effects of smoking on heart rate, ST segment changes, arrhythmias and cardiac autonomic function as measured by HRV using ambulatory ECG (Holter) monitoring.

\section{MATERIAL AND METHODS}

Current smokers presenting to cardiology outpatients unit with atypical chest pain were recruited in the study. After a baseline examination and investigations, all the patients underwent a treadmill exercise test. Patients with a negative or mildly positive exercise test were included in the study. Patients with established obstructive coronary artery disease, unstable coronary syndromes, moderately positive to strongly positive exercise test (Duke treadmill score $<-11$ ), inability to exercise, significant arrhythmias and baseline ECG changes like left bundle branch block and ST depression $>1 \mathrm{~mm}$ that preclude interpretation of treadmill exercise test (TMT) were excluded.

All these patients underwent a $24 \mathrm{~h}$ Holter monitoring, after providing an informed consent. The study was approved by Institute's ethics committee. Skin preparation, electrode placement, and related protocols were similar to the established guidelines. Patients returned home and maintained a normal daily routine during the Holter monitoring. The participants were asked to record the time of smoking and relevant symptoms. ECGs were recorded digitally (sampling rate of 1024 samples per second) on removable flash cards using a light-weight, 12-channel, ambulatory ECG monitor (Delma Reynolds Life Card CF). The signal was recorded continuously throughout the study period. The ECG digital recordings were processed using PC-based software (Life Card). Only normal-to-normal beat $(\mathrm{NN})$ intervals were included in the analysis. The Holters were analysed for the minimum, maximum and average heart rates, ST/T changes and arrhythmias. Heart rate and ischaemic changes were specifically noted $10 \mathrm{~min}$ prior to the event of smoking and every $10 \mathrm{~min}$ for next $60 \mathrm{~min}$ following every episode of smoking. Changes during chest pain or dyspnoea or palpitation and syncope were also noted. Two investigators independently analysed all the Holter tracings.

HRV measures were calculated using time-domain measures. The parameters of HRV measured included SDNN (standard deviation of all NN intervals), SDANN (standard deviation of average $\mathrm{NN}$ intervals during 5 min monitoring), RMSSD (root mean square value of square differences between neighboring $\mathrm{NN}$ intervals), SDNN index (mean standard deviation of all NN intervals from 5 min segments), SDSD ms (standard deviation of neighboring $\mathrm{NN}$ interval differences), NN 50 (count of coupled neighboring $\mathrm{NN}$ intervals differing more than $50 \mathrm{~ms}$ in length), p NN 50 (NN 50 divided by the total count of NN intervals), HRV index (total count of NN intervals divided by the histogram height) and TINN (triangle base length gained by triangular interpolation of histogram on the principle of smallest square method). Statistical methods including SDNN, SDANN and RMSSD are affected by the quality of the QRS, but geometrical methods are free of these artifacts. HRV index is a relative count of NN interval with most frequently occurring length. Main advantage of geometrical method resides in its independence from the quality of analysed NN interval. Disadvantage is that it requires long period of recording, not mere $20 \mathrm{~min}$ of recording.

We used the HRV data of 15 normal participants (agematched to the initial 15 patients) undergoing Holter monitoring for the control group. After the completion of Holter, the patients were strongly counseled to quit smoking.

\section{Statistical analysis}

The results are expressed as mean $\pm \mathrm{SD}$ or percentages. Repeated-measures ANOVA was used to assess changes over time and paired t tests were used to assess specific changes. Unpaired t test or Mann-Whitney test (wherever applicable) was applied for intergroup comparison of HRV parameters. A $\mathrm{p}$ value of $<0.05$ was considered as significant. SPSS Software V.11.0 (SPSS Inc) was used for analysis.

\section{RESULTS}

We enrolled a total of 31 men with an average age of 49 years with approximately one-fourth of them being bidi smokers. Bidis are cheaper Indian form of hand-rolled cigarettes using dried betel leaves. They contain lesser amount of tobacco, but greater concentration of nicotine as compared to regular cigarettes and are equally harmful. The baseline characteristics are summarised in table 1 . The average heart rate throughout the $24 \mathrm{~h}$ was $80.3 \pm 9.5 \mathrm{bpm}$, and the average maximum and minimum heart rates were $119.3 \pm 15.7$ and $57.5 \pm 8.9 \mathrm{bpm}$, respectively. Mean heart rate $10 \mathrm{~min}$ before smoking was $83.8 \pm 13.7 \mathrm{bpm}$, which increased to $90.5 \pm 16.4 \mathrm{bpm}$ on initiation of smoking and came down

\begin{tabular}{|c|c|c|}
\hline Characteristics & Smoking group & Control group \\
\hline Age (years) & $49.8 \pm 10.5$ & $45.7 \pm 10.6$ \\
\hline Male & $31(100 \%)$ & $15(100 \%)$ \\
\hline \multicolumn{3}{|l|}{ Risk factors } \\
\hline Hypertension & $5(16 \%)$ & $3(20 \%)$ \\
\hline Diabetes mellitus & $1(3 \%)$ & $1(6.7 \%)$ \\
\hline Dyslipidaemia & $2(6 \%)$ & $2(13.3 \%)$ \\
\hline \multicolumn{3}{|l|}{ Symptoms } \\
\hline Angina & $5(16 \%)$ & $2(13.3 \%)$ \\
\hline Dyspnoea & $5(16 \%)$ & $3(20 \%)$ \\
\hline Syncope & $2(6 \%)$ & $2(13.3 \%)$ \\
\hline Presyncope & $1(3 \%)$ & - \\
\hline \multicolumn{3}{|l|}{ Smoking } \\
\hline Quantity/day & $5.08 \pm 2.79$ & - \\
\hline
\end{tabular}


Table 2 Time onset of increase in heart rate from the baseline during smoking

\begin{tabular}{lllll}
\hline & Mean HR & Mean $\uparrow$ in HR & SE & p Value \\
\hline Prior to smoking & 83.8 & & & \\
During smoking & 90.5 & 6.7 & 1.1 & $<0.0001$ \\
10 min after smoking & 88.2 & 4.4 & 0.7 & $<0.0001$ \\
20 min after smoking & 85.6 & 1.8 & 0.7 & 0.15 \\
30 min after smoking & 84.5 & 0.7 & 0.7 & 0.32 \\
\hline
\end{tabular}

to $88.2 \pm 15.3 \mathrm{bpm} 10 \mathrm{~min}$ after smoking, $85.6 \pm 14.6 \mathrm{bpm}$ $20 \mathrm{~min}$ after smoking and $84.5 \pm 14.4 \mathrm{bpm}$ after $30 \mathrm{~min}$ of smoking. Pair-wise comparisons of heart rate showed that heart rate rises within $10 \mathrm{~min}$ of smoking and remained elevated for the next $20 \mathrm{~min}$ and returned to baseline after $30 \mathrm{~min}$ (table 2).

Arrhythmias per hour were analysed and correlated with smoking episodes. Six (19.4\%) patients did not have even a single ectopic. There was significant increase in arrhythmias during the hour in which cigarette was smoked and an hour after that (figure 1). Smoking significantly increased the total number of ectopics, summed supraventricular ectopics (SVEs) and ventricular premature complexes (VPCs), from a mean of $5.3 / \mathrm{h}$ prior to smoking to $9.8 / \mathrm{h}$ in the hour smoked to $11.3 / \mathrm{h}$ during the hour after smoking. When the ectopics were analysed individually, there was a significant increase in SVEs after smoking. The mean number of SVE was $4.1 / \mathrm{h}$ prior to smoking, $7.1 / \mathrm{h}$ during the hour of smoking and $6.9 / \mathrm{h}$ in the hour after smoking $(p<0.0001)$. However, increase in the mean number of VPCs which was $1.2 / \mathrm{h}$ prior to smoking, $2.7 / \mathrm{h}$ during hour of smoking and 4.3 in next hour of smoking, did not reach statistical significance $(p=0.17)$.

The number of patients having SVEs also increased following smoking. SVEs occurred in $20.4 \%$ of patients during the hour of smoking and $25.3 \%$ of patients in the following hour as compared to $10.2 \%$ of patients in non-smoking hours $(\mathrm{p}<0.001)$. However, the proportion of patients having VPC did not change significantly. VPCs occurred in $7.6 \%$ of patients during the hour of smoking and $5.7 \%$ of patients in the following hour as compared to $5.3 \%$ of patients in non-smoking hours $(\mathrm{p}=0.17)$.

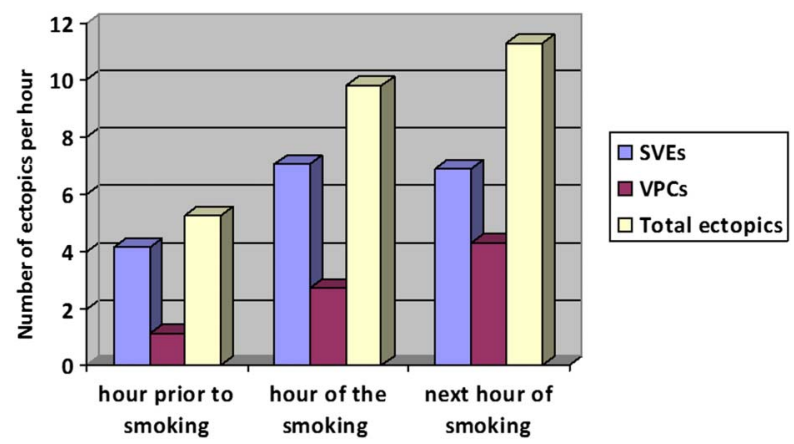

Figure 1 Analysis of arrhythmias per hour prior to smoking, hour of the smoking and in the next hour of smoking.
A run of non-sustained ventricular tachycardia (NSVT) was recorded in one patient. NSVT developed within $20 \mathrm{~min}$ of smoking; this might be related to smoking. None of these episodes were symptomatic.

\section{ST-T changes}

Ischaemic changes were monitored during Holter recording and correlated with the time of smoking. Of the 31 patients, three patients $(9.7 \%)$ had episodes of significant (1-2 mm) ST segment and T wave changes in inferior leads during and after smoking. The onset was 8-12 min after smoking and lasted for 28-120 min. One patient had dynamic ST-T segment changes each time he smoked. The ST segment changes did not recur during subsequent episodes of smoking in the other patients. No other episode of ST/T changes were noted unrelated to smoking. A CT angiogram was performed in the three patients with ST-T changes which did not reveal any significant obstructive CAD.

\section{Heart rate variability}

HRV analysis was done on time domain method. HRV parameters were within normal range, except the HRV index (table 3). Smokers had a significantly lower HRV index as compared to non-smoking normal controls $(15.2 \pm 5.3$ in smokers vs $19.4 \pm 3.6$ in healthy controls; $\mathrm{p}$ value $=0.02)$.

\section{DISCUSSION}

Smoking is the most important risk factor for the coronary artery disease. Smoking is known to have multiple ECG effects; however, the temporal relationship of the ECG changes to an act of smoking is not known. In the present study, the heart rate rose within $10 \mathrm{~min}$ of

Table 3 HRV analysis in smokers and in normal controls

\begin{tabular}{lccl}
\hline Measure & Smokers $(\mathbf{n}=\mathbf{3 1})$ & Controls $(\mathbf{n}=\mathbf{1 5})$ & $\mathbf{p}$ Value \\
\hline HRV index & $15.2 \pm 5.3$ & $19.4 \pm 3.6$ & 0.02 \\
SDNN & $116.7 \pm 41.2$ & $126.9 \pm 23.3$ & 0.18 \\
SDANN & $109.5 \pm 42.5$ & $116.0 \pm 17.7$ & 0.27 \\
RMSSD & $36.1 \pm 16.9$ & $34.9 \pm 19.9$ & 0.67
\end{tabular}

HRV index, heart rate variability index (total count of NN intervals divided by the histogram height); RMSSD, root mean square value of square differences between neighboring NN intervals; SDANN, standard deviation of average NN intervals during 5 min monitoring SDNN, standard deviation of all NN intervals. 
smoking and remained elevated for up to $20 \mathrm{~min}$ and came to baseline after $30 \mathrm{~min}$. Acute increase in heart rate is well documented by invasive studies also. ${ }^{9}$ The heart rate also increases following consumption of smokeless forms of tobacco, like chewing of tobacco. ${ }^{10}$ In fact, fetal heart rates also increase following smoking by pregnant mothers. ${ }^{11}$

Smoking acutely increased supraventricular arrhythmias also. The number of SVEs per hour increased, and also more number of smokers had SVEs recorded during the period of smoking. Studies had shown that smoking increases conduction velocities, and decreases effective refractory period by decreasing parasympathetic tone in atrial conduction system and also increases sympathetic tone which could be responsible for the excess SVEs. ${ }^{12}$ Smoking also increased ventricular arrhythmias, but this increase did not reach statistical significance. One of our patient developed NSVT within 20 min of smoking. It is difficult to ascertain the cause and effect relationship, as only a single episode was observed.

Significant ST-T changes were observed in three of our patients. None of these three patients developed chest pain during the ischaemic episodes. Ischaemic episodes during smoking frequently remained inert. ${ }^{13}{ }^{14}$ We did not observe any episode of ST segment elevation during or following smoking. The mechanisms by which smoking is likely to contribute to vascular events and ST-T changes include-induction of a hypercoagulable state, increased myocardial work, carbon monoxide mediated reduction in $\mathrm{O}_{2}$ carrying capacity of the blood, induction of endothelial dysfunction, coronary vasoconstriction and catecholamine release. ${ }^{15}$ The prognostic significance of these ST-T changes in the absence of obstructive coronary artery disease needs to be established in smokers.

The studied HRV parameters including SDNN, SDANN and RMSSD were within normal range, but HRV index was significantly less in smokers. SDNN and HRV index are the parameters expressing the overall HRV. SDANN is a marker of spectral components with a long period and RMSSD is a marker of components with a short period. ${ }^{7816}$ These methods do not substitute each other, but supplant each other mutually. HRV index is a more sensitive and specific method for HRV analysis, as it uses geometrical method. ${ }^{16}$ As in the present study, when $24 \mathrm{~h}$ of Holter is used, HRV index remains as an important parameter of HRV. ${ }^{16}$

Autonomic nervous system may play an important role in cardiovascular diseases. HRV is useful in non-invasive quantification of autonomic nervous system. ${ }^{8}$ Large epidemiological studies have also linked an increased risk of coronary artery disease, death and cardiac mortality with decreased HRV in general populations. ${ }^{17}{ }^{18}$ Although it is clear that low HRV has a negative prognostic impact, it is important to point out that causality and mechanisms have not been established. Decreased HRV among smokers is also shown in a few studies. A study of acute tobacco smoke exposure to small numbers of volunteers has shown significant HRV changes. ${ }^{19}$ Studies have also documented increase in HRV immediately after smoking cessation. ${ }^{20} 21$ The component of tobacco smoke that is responsible for autonomic dysfunction is not known. Carbon monoxide was implemented in some studies. Role of nicotine is still not clear in the causation of autonomic dysfunction, since nicotine patches that release high level of nicotine are shown to have minimal effect on HRV. RSP may be the main culprit. A study of healthy volunteer had shown that $100 \mu \mathrm{g} / \mathrm{m}^{3}$ increase in $4 \mathrm{~h}$ RSP exposure was associated with approximately a $25 \mathrm{~ms}$ decline in both SDNN and r-MSSD. ${ }^{19}$

\section{CONCLUSIONS}

Smoking increases heart rate significantly which remains elevated for $20 \mathrm{~min}$ and returns to baseline at $30 \mathrm{~min}$. It also increases combined supraventricular and ventricular arrhythmias. In addition, ischaemic ST-T changes lasting for half-an-hour to $2 \mathrm{~h}$ was observed during smoking. Spectral parameters of HRV analysis of smoker remained within normal limits, but more importantly geometrical parameter-HRV indexshowed significant abnormality.

Contributors SR wrote the protocol, was involved in the analysis and interpretation of the data and wrote the manuscript. BB initiated the study, guided the analysis and interpretation of the data and critically modified the manuscript. KB and AKD collected the data and wrote the first manuscript. $A R$ and NN were involved in interpreting the Holter study. AR, NN, SS and SS critically evaluated the manuscript and added important intellectual content and finally approved the manuscript. BB is the guarantor.

Funding This research received no specific grant from any funding agency in the public, commercial or not-for-profit sectors.

Competing interests None.

Patient consent Obtained.

Ethics approval Institute's ethics committee.

Provenance and peer review Not commissioned; externally peer reviewed.

Data sharing statement No additional data are available.

\section{REFERENCES}

1. Prasad DS, Kabir Z, Dash AK, et al. Smoking and cardiovascular health: a review of the epidemiology, pathogenesis, prevention and control of tobacco. Indian J Med Sci 2009;63:520-33.

2. Bazzano LA, He J, Muntner $P$, et al. Relationship between cigarette smoking and novel risk factors for cardiovascular disease in the United States. Ann Intern Med 2003;138:891-7.

3. Akishima S, Matsushita S, Sato F, et al. Cigarette-smoke-induced vasoconstriction of peripheral arteries: evaluation by synchrotron radiation microangiography. Circ $J$ 2007;71:418-22.

4. Caralis DG, Deligonul U, Kern MJ, et al. Smoking is a risk factor for coronary spasm in young women. Circulation 1992;85:905-9.

5. Ezzati M, Henley SJ, Thun MJ, et al. Role of smoking in global and regional cardiovascular mortality. Circulation 2005;112:489-97.

6. Thayer JF, Yamamoto SS, Brosschot JF. The relationship of autonomic imbalance, heart rate variability and cardiovascular disease risk factors. Int J Cardiol 2010;141:122-31.

7. Majercak I. The use of heart rate variability in cardiology. Bratis/ Lek Listy 2002;103:368-77.

8. Lahiri MK, Kannankeril PJ, Goldberger JJ. Assessment of autonomic function in cardiovascular disease: physiological basis and prognostic implications. J Am Coll Cardiol 2008;51:1725-33.

9. Zhu BQ, Parmley WW. Hemodynamic and vascular effects of active and passive smoking. Am Heart J 1995;130:1270-5. 
10. Ramakrishnan S, Thangjam R, Roy A, et al. Acute effects of tobacco chewing on the systemic, pulmonary and coronary circulation. Am J Cardiovasc Drugs 2011:11:109-14.

11. Graça LM, Cardoso CG, Clode N, et al. Acute effects of maternal cigarette smoking on fetal heart rate and fetal body movements felt by the mother. J Perinat Med 1991;19:385-90.

12. D'Alessandro A, Boeckelmann I, Hammwhöner M, et al. Nicotine, cigarette smoking and cardiac arrhythmia: an overview. Eur J Prev Cardiol 2012;19:297-305.

13. Conti CR, Bavry AA, Petersen JW. Silent ischemia: clinical relevance. J Am Coll Cardiol 2012;59:435-41.

14. Valle GA, Lemberg L. Silent ischemia: a clinical update. Chest 1990;97:186-91.

15. Ambrose JA, Barua RS. The pathophysiology of cigarette smoking and cardiovascular disease: an update. J Am Coll Cardiol 2004;43:1731-7.

16. Task force of the European Society of Cardiology and the North American Society of Pacing and Electrophysiology. Heart rate variability: standards of measurement, physiological interpretation and clinical use. Circulation 1996;93:1043-65.

17. Dekker JM, Crow RS, Folsom AR, et al. Low heart rate variability in a 2-minute rhythm strip predicts risk of coronary heart disease and mortality from several causes: the ARIC Study. Atherosclerosis risk in communities. Circulation 2000;102:1239-44.

18. de Bruyne MC, Kors JA, Hoes AW, et al. Both decreased and increased heart rate variability on the standard 10-second electrocardiogram predict cardiac mortality in the elderly: the Rotterdam Study. Am J Epidemiol 1999;150:1282-8.

19. Pope CA 3rd, Eatough DJ, Gold DR, et al. Acute exposure to environmental tobacco smoke and heart rate variability. Environ Health Perspect 2001;109:711-16.

20. Stein PK, Rottman JN, Kleiger RE. Effect of $21 \mathrm{mg}$ transdermal nicotine patches and smoking cessation on heart rate variability. Am J Cardiol 1996;77:701-5.

21. Yotsukura $\mathrm{M}$, Koide $\mathrm{Y}$, Fujii $\mathrm{K}$, et al. Heart rate variability during the first month of smoking cessation. Am Heart J 1998;135:1004-9. 